\title{
ANALYSIS OF WELD JOINT DEFORMATIONS BY OPTICAL 3D SCANNING
}

\author{
JÁn UrminskÝ*, MiroslaV JáŇA, Milan Marônek, Ladislav Morovič \\ Slovak University of Technology in Bratislava, Faculty of Materials Science and Technology in Trnava, Institute \\ of Production Technologies, J. Bottu 25, 91724 Trnava, Slovakia \\ * corresponding author: jan.urminsky@stuba.sk
}

\begin{abstract}
This paper presents an analysis of weld joint deformation using optical 3D scanning. The weld joints of bimetals were made by explosion welding (EXW). GOM ATOS II TripleScan SO MV320 equipment with measuring volume $320 \times 240 \times 240 \mathrm{~mm}, 5.0$ MPix camera resolution and GOM ATOS I 350 with a measuring volume of $250 \times 200 \times 200 \mathrm{~mm}, 0.8$ MPix camera resolution were used for experimental deformation measurements of weldments. The scanned samples were compared with reference specimens. The angular and transverse deformation were visualized by colour deviation maps. The maximum observed deformations of the weld joints ranged from -1.96 to $+1.20 \mathrm{~mm}$.
\end{abstract}

KEYWORDS: analysis of weldment deformation; explosion welding; 3D scanning; GOM ATOS.

\section{INTRODUCTION}

Non-uniform heating of welded components due to the thermal cycle of welding, thermal expansion during heating and cooling with the clamping stiffness and the formation of non-equilibrium structures in the heat affected zone (HAZ) cause the formation of transient, variable and permanent stresses. These stresses lead to a local or total deformation of the weldments. The resultant deformations can be classified as longitudinal, transverse and angular deformations, according to their position. Angular deformations are adverse from all group and can degrade the utility of the weldment. The size of the angular deformation depends especially on the design of the weld joint. The correct structural design and positioning of welds in terms of stress are a precondition for making high quality weld structures. Generally, deformations deteriorate the properties of the weldment [1, 2].

The residual stress can be measured by an electrical resistance strain gauge, by $\mathrm{X}$-ray diffraction analysis, by the ultrasonic method, and also by standard methods of contact metrology. Callipers, protractors and dial indicators are used for detecting shape and position deviations. These methods for determining the dimensional and shape deviations of a weldment are mostly time consuming, and require repeated measurements of the whole area. Nowadays, products are checked by time-saving quality control methods $3 \mathbf{3}]$.

The new quality control methods implemented into continuous production processes are based on coordinate measurements. Modern optical 3D scanners are now more frequently used than standard traditional measurement methods. These digitization devices are based on obtaining of surface coordinate points by scanning the surface illuminated by structured light. The spatial coordinates of points forming the surface of the scanned object are determined by active triangulation. The digital model of the object is formed obtained by polygonising the cloud of points that are obtained. In order to scan reflective surfaces and transparent objects, antireflection layers are applied to the surface of the measured object.

The final deformation can then be visualized by colour deviation maps. This paper evaluates the suitability of a GOM ATOS 3D optical scanner for measuring the deformations of weld joints [6]

\section{EXPERIMENT}

Weld joints were produced by explosion welding. The flyer plate was made of $\mathrm{Cr}-\mathrm{Ni}$ austenitic steel sheet. AZ31B Mg magnesium alloy, AW-1050A aluminium alloy and GJS-500-7 ductile iron were used as parent plates. The chemical compositions of the materials are presented in Tables 1 to 4 .

Austenitic steel was selected on the basis of its corrosion resistance and its applicability from cryogenic temperatures to high temperatures. AZ31B alloy has a good plastic properties and weldability.

AZ31B is used mainly for formed non-heat treated components. $\mathrm{Cr}-\mathrm{Ni}$ steel $-\mathrm{Mg}$ alloy bimetals are used in the automotive industry. AW-1050A alloy is suitable for cold forming. In combination with $\mathrm{Cr}-\mathrm{Ni}$ steel, it is applied in the automotive industry as a semi-product for the production of bumpers and car doors, where increased corrosion resistance, low weight and aesthetic look are required. These combination of materials are also used in cryogenic environments in the chemical industry and in the shipbuilding industry. GJS-500-7 ductile iron shows good machinability and low abrasion resistance. This combination is used for producing bimetal valves, and it significantly reduces the manufacturing cost. The dimensions of the welded materials are shown in Table 5 [10 13.

The weld joints were prepared in cooperation with the Research Institute of Industrial Chemistry in Pardubice-Semtin. There are several parameters that 


\begin{tabular}{lccccccc}
\hline Element & $\mathbf{C}$ & $\mathbf{M n}$ & $\mathbf{S i}$ & $\mathbf{C r}$ & $\mathbf{N i}$ & $\mathbf{P}$ & $\mathbf{S}$ \\
\hline wt. \% & $\max .0 .07$ & $\max .2 .0$ & $\max .1 .0$ & $17.0-20.0$ & $9.0-11.5$ & $\max .0 .045$ & $\max .0 .03$ \\
\hline
\end{tabular}

TABle 1. Chemical composition of the Cr-Ni austenitic steel [10].

\begin{tabular}{lccccccc}
\hline Element & $\mathbf{M g}$ & $\mathbf{A l}$ & $\mathbf{Z n}$ & $\mathbf{M n}$ & $\mathbf{S i}$ & $\mathbf{N i}$ & $\mathbf{F e}$ \\
\hline wt. $\%$ & 97.05 & $2.5-3.5$ & $0.6-1.4$ & $0.2-1.0$ & max. 0.1 & max. 0.005 & max. 0.005 \\
\hline
\end{tabular}

TABle 2. Chemical composition of the AZ31B Mg alloy [11].

\begin{tabular}{lccccccc}
\hline Element & Al & Fe & Si & Zn & Cu & Ti & Fe \\
\hline wt. $\%$ & 99.5 & max. 0.4 & $\max .0 .3$ & $\max .0 .07$ & $\max .0 .05$ & $\max .0 .05$ & $\max .0 .005$ \\
\hline
\end{tabular}

TABLE 3. Chemical composition of the AW-1050A Al alloy [1].

\begin{tabular}{lccccccc}
\hline Element & $\mathbf{C}$ & $\mathbf{M n}$ & $\mathbf{S i}$ & $\mathbf{P}$ & $\mathbf{S}$ & $\mathbf{T i}$ & $\mathbf{F e}$ \\
\hline wt.\% & $2.7-3.7$ & $0.3-0.7$ & $0.8-2.9$ & $\max .0 .1$ & $\max .0 .02$ & $\max .0 .05$ & $\max .0 .005$ \\
\hline
\end{tabular}

TABLE 4. Chemical composition of the GJS-500-7 ductile iron [12.

\begin{tabular}{clll}
\hline Sample & \multicolumn{1}{c}{ Flyer plate } & \multicolumn{2}{c}{ Parent plate } \\
\hline 1 & Cr-Ni steel $176 \times 146 \times 1 \mathrm{~mm}$ & AW-1050A & $146 \times 116 \times 15 \mathrm{~mm}$ \\
2 & Cr-Ni steel $250 \times 135 \times 1 \mathrm{~mm}$ & GJS-500-7 & $200 \times 95 \times 24 \mathrm{~mm}$ \\
3 & Cr-Ni steel $370 \times 260 \times 1 \mathrm{~mm}$ & AZ31B & $190 \times 155 \times 20 \mathrm{~mm}$ \\
\hline
\end{tabular}

TABLE 5. Dimensions of the welded materials.

\begin{tabular}{clr}
\hline Bimetal & Combination of materials & Dimension $(\mathbf{L} \times \mathbf{W} \times \mathbf{H})$ \\
\hline 1 & Cr-Ni steel - AW-1050A & $116 \times 146 \times 16 \mathrm{~mm}$ \\
2 & Cr-Ni steel - GJS-500-7 & $95 \times 200 \times 25 \mathrm{~mm}$ \\
3 & Cr-Ni steel - AZ31B & $155 \times 190 \times 21 \mathrm{~mm}$ \\
\hline
\end{tabular}

TABLE 6. Dimensions of the bimetals.

affect the quality and the character of weld joints, in particular the detonation velocity, the welding speed, the set-up distance, the geometrical dimensions and the properties of the explosive charge. A parallel welded materials set-up was used (Figure 1a). The explosive charge was initiated by a Starline 12 detonating fuse with a detonation speed of $6800 \mathrm{~m} \mathrm{~s}^{-1}$. The following explosive charges were used: Semtex $10 \mathrm{SE}$ for the Cr-Ni steel - AZ31B alloy bimetal; Semtex S 25 for the Cr-Ni steel- GJS-500-7 bimetal; and Semtex S 35 for Cr-Ni steel - AW-1050A bimetal. The parameters and explosion welding conditions that were used are presented in Figure 11 b-d [10, 12, 13]. Immediately after the detonation of the explosive charge, the flyer material is deformed and is accelerated toward the parent plate. Welded materials therefore deform before the weld joint is formed.

Experimental measurements of the deformation of welded joints were performed using GOM ATOS II TripleScan SO MV320 equipment (measuring volume: $320 \times 240 \times 240 \mathrm{~mm}$, camera resolution $2448 \times 2050$ pixels (5.0 MPx)) and using GOM ATOS I 350, (measuring volume: $250 \times 200 \times 200 \mathrm{~mm}, 1032 \times 776$ pixels $(0.8 \mathrm{MPx}))$, owned by the Slovak University of Technology in Bratislava, Faculty of Materials Science and Technology in Trnava, (Figure 2] [6, 7].

Before making the measurements, it was necessary to clean up the bimetals. In order to increase the precision of assembly of the individual scans from various measuring positions, non-coding reference points were stuck on to the cleaned surface of the bimetal. An anti-reflective coating was sprayed on the bimetal surface to prevent light reflections during scanning. The bimetal was placed on the rotary table and was scanned in 12 positions (Figure 3a). A 3D digital model in .stl format was generated by the scanner after obtaining a cloud of points and subsequent polygonization (Figure 3p). To detect the deformation of the weld joint, a comparison was made between the deformed bimetal model (after welding) and CAD model (before welding) using GOM ATOS Professional v7.5 software. Colour deviation maps were generated as 

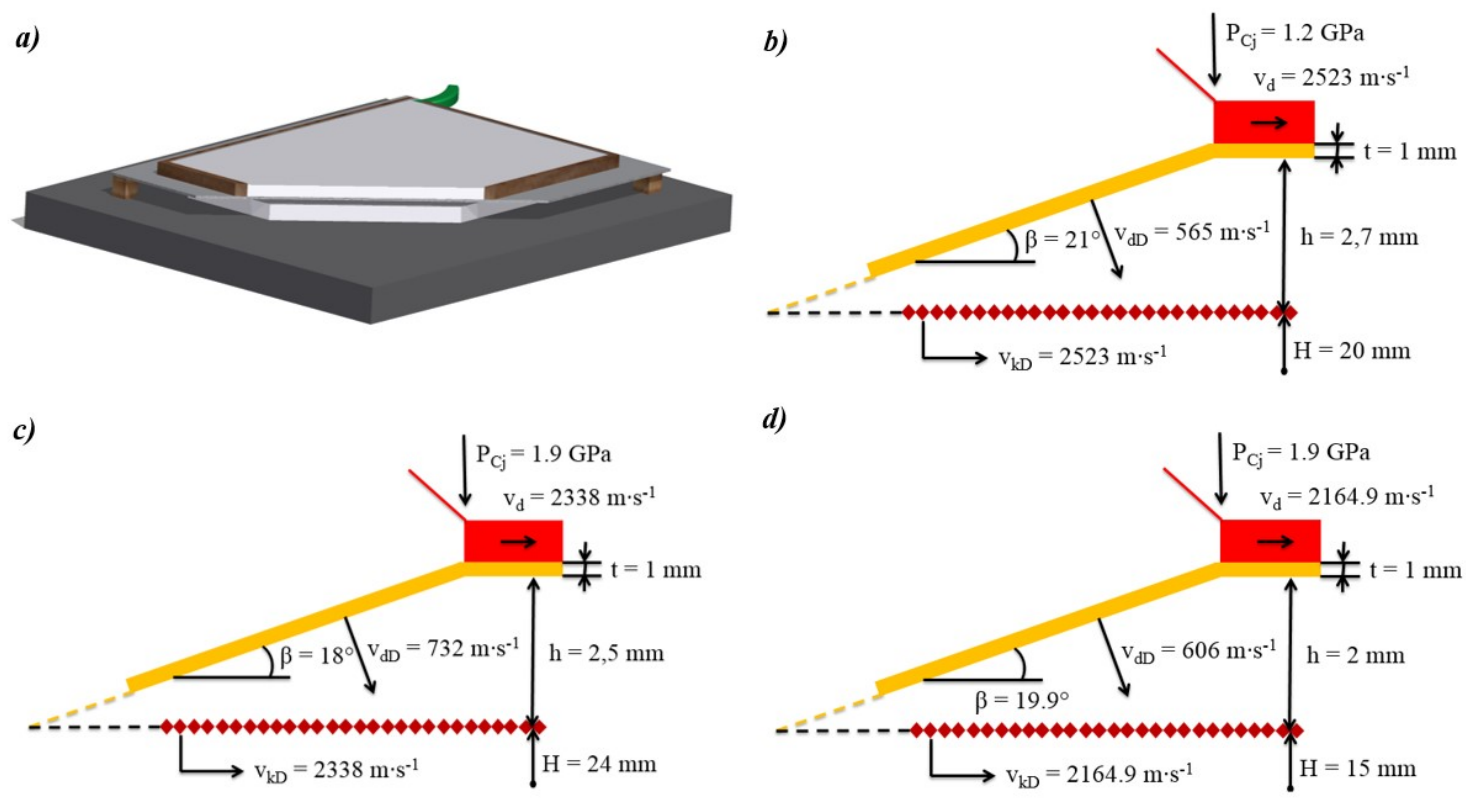

FiguRE 1. Welding parameters; a) parallel set-up of welded materials; b) explosion welding parameters, sample 3; c) explosion welding parameters, sample 2; d) explosion welding parameters, sample 1; [10].
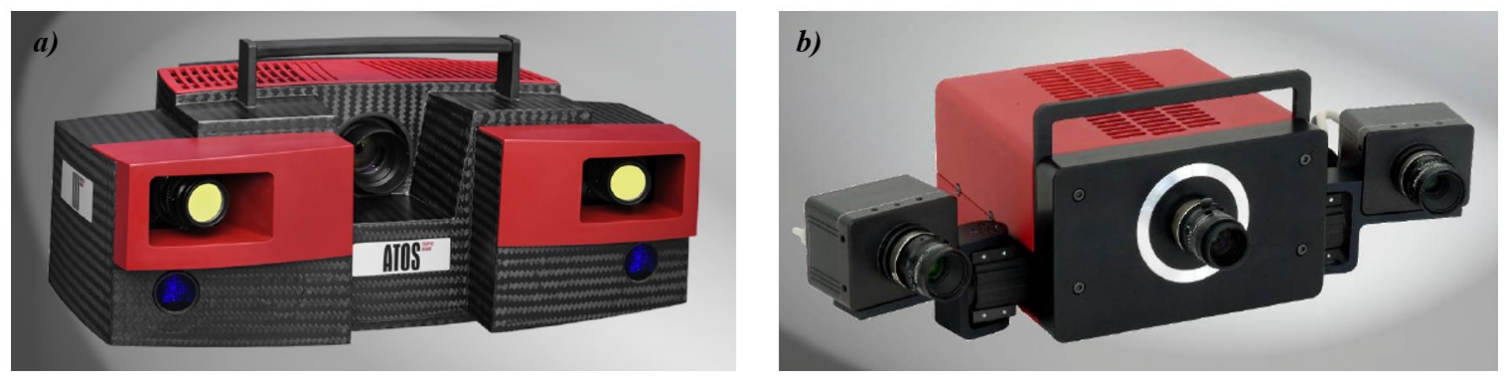

Figure 2. The heads of 3D optical scanners; a) GOM ATOS II TripleScan SO MV320; b) GOM ATOS I 350 6, 7 .

an output (Figures 4 to 6). The quality of the weld interface and the total quality of the bimetals that were produced were evaluated by ultrasonic testing, by light microscopy, by micro-hardness measurements, and by EDX and EBSD analyses.

\section{Results}

Deformation measurements were made of weld joints made by explosion welding. The dimensions of the scanned bimetals are shown in Table 6 .

Bimetal 1 was scanned using a GOM ATOS I 350 device. Bimetals 2 and 3 were scanned using a GOM ATOS II TripleScan device. Transverse, longitudinal and angular deformations were observed as the shape deviations on the weld joints. The deformations of each bimetal were caused by detonation pressure and by the final high velocity collision of the welded materials. Intensive plastic deformation occurred in the weld joint interface during formation of the weld joint. The scanned bimetals were compared with individual reference samples created by CAD software. The beginning and the direction of the explosive initiation is illustrated by red arrow on the scanned bimetal. Deformations of various patterns were observed on bimetal 1 (Figure 4). The greatest deformations were seen on the edges of the bimetal. The bimetal lost its flatness due to deformation in direction of the $z$-axis and transverse deformation in the $x$-axis direction. Angular deformations were not observed throughout the thickness of the material.

Deformations of various sizes were identified in individual planes perpendicular to the thickness of the bimetal. The maximum deformations were observed on the top of the bimetal, and varied from -2.00 to $+0.40 \mathrm{~mm}$. The deformations on the bottom side of the bimetal ranged from -0.80 to $+1.07 \mathrm{~mm}$.

The colour deviation map of bimetal 2 (Figure 5) revealed angular deformation (displacement in the direction of the $z$-axis). The most significant deformation occurred on the surface of the bimetal, and ranged from -0.20 to $+1.00 \mathrm{~mm}$. The deformation range on the bottom side of the bimetal varied from -0.40 to $+0.60 \mathrm{~mm}$.

The angular deformations were also detected after evaluation of bimetal 3 (Figure 6). At the corner adjacent to explosive initiation place ( $x$-axis direction) a surface "hump" was created. This deformation was created as a consequence of explosive fuse detonation. 
a)

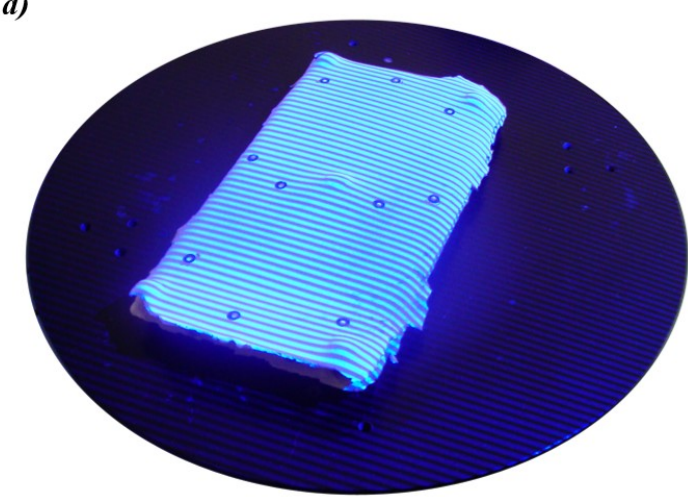

b)

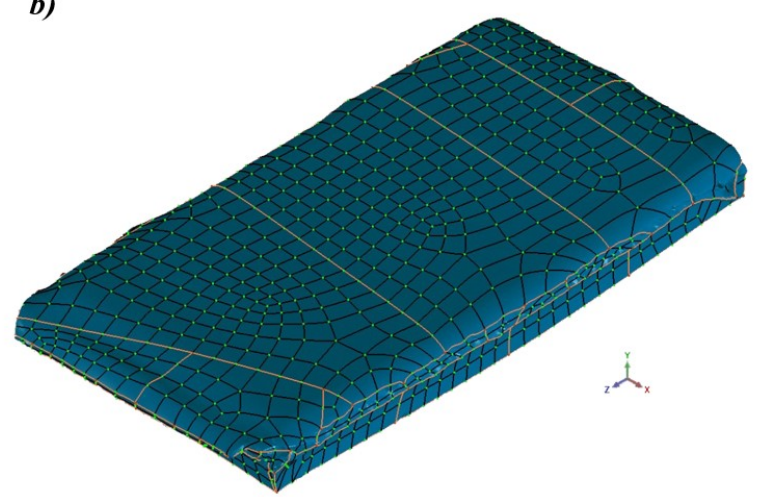

FiguRE 3. Digitization process of the welded bimetal); a) the scanning process provided by structured light and non-coded referential points; b) the scanned object after meshing [10].
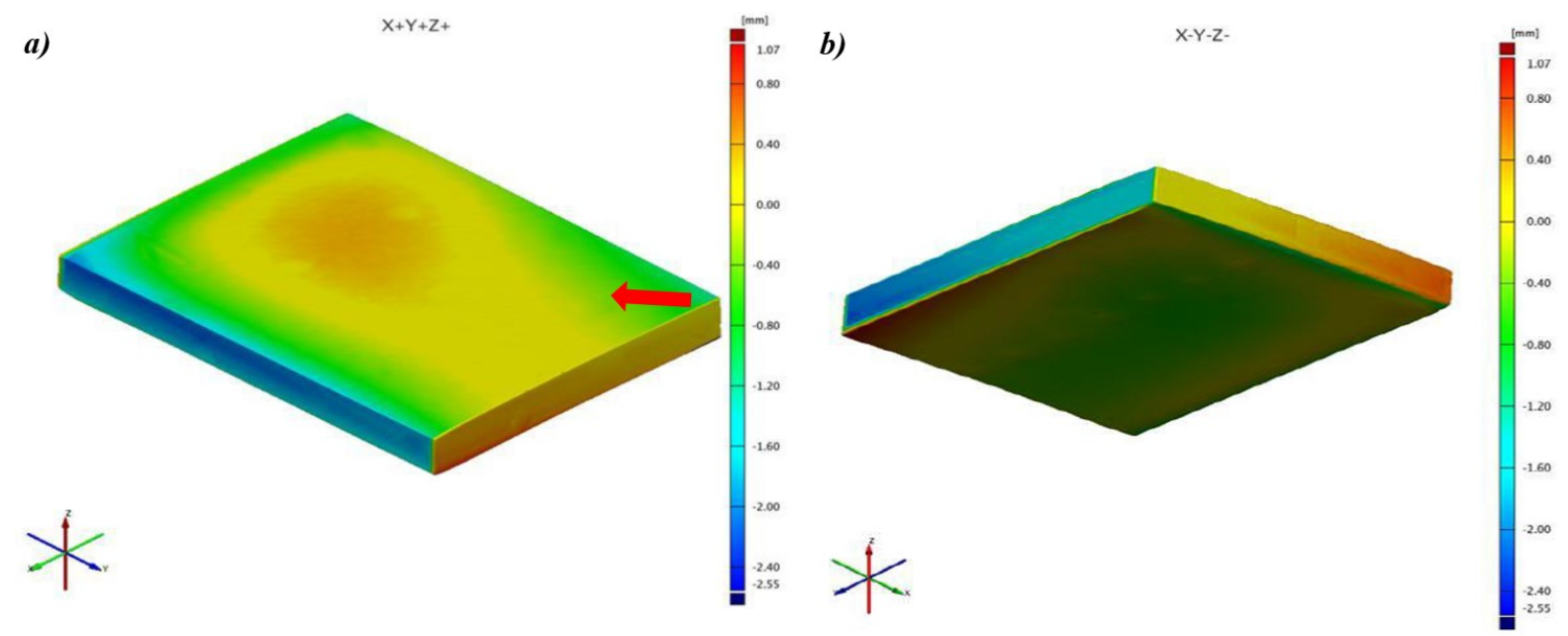

Figure 4. The colour deviation map of the bimetal; a) top view, b) bottom view 13 .

However, for the statement verification, the more experiments under the same conditions should be carried out. The deformations showed various values of the top and bottom side of the bimetal. The deformation values on the top side were in range from -1.25 to $+1.20 \mathrm{~mm}$. The value of the hump amplitude was $1.55 \mathrm{~mm}$ and no defect was observed in this place of bimetal. The deformation values of on the bottom side of bimetal ranged from -1.96 to $+0.40 \mathrm{~mm}$ in comparison to the reference sample.

The various deformation values of the bimetals can be explained by different pressure of detonating explosive charge. The detonating pressure was sufficient for creating the weld joint, but was not high enough to achieve similar deformation on the opposite side of the bimetal. The angular deformations were decreasing towards the bottom side of the parent material. There is obvious, that deformation values depend on mechanical properties of welded materials.

\section{Conclusion}

Devices GOM ATOS II TripleScan SO MV320 and GOM ATOS I 350 have versatile use in quality evaluation of manufacturing products. The results confirmed that these devices can be used also for evaluation of the weld joints. The data analysis showed, that the scanning precision was adequate not only for evaluation of deformations, but also to reveal the details of the weld joints. Used 3D scanners provide a sufficient amount of input data for the analysis of weldment's deformation and they are able to accurately determine the size and direction of the bimetal distortion. However, the scanners are limited in measuring volume. It is possible to scan an area in range from $38 \times 29$ to $2000 \times 1500 \mathrm{~mm}$, with a suitable optical configuration. For larger bimetals, it is necessary to use the scanning equipment with appropriate measuring volume. TriTop, Scan Box and ATOS Plus systems could be suitable alternatives. The photogrammetric TriTop system can scan area of $10 \times 10 \mathrm{~m}$. Its disadvantage is necessity to use calibration bars, which in relation to scanned object cannot be moved during scanning. The Scan Box unit allows scanning a sample with maximum dimension of $3 \mathrm{~m}$. The ATOS Plus system represents hardware extension based on photogrammetry for 3D scanner ATOS Triple Scan and ATOS Core. The dimensions of the scanned areas range from $300 \times 225$ to $2000 \times 3000 \mathrm{~mm}$. 
a)

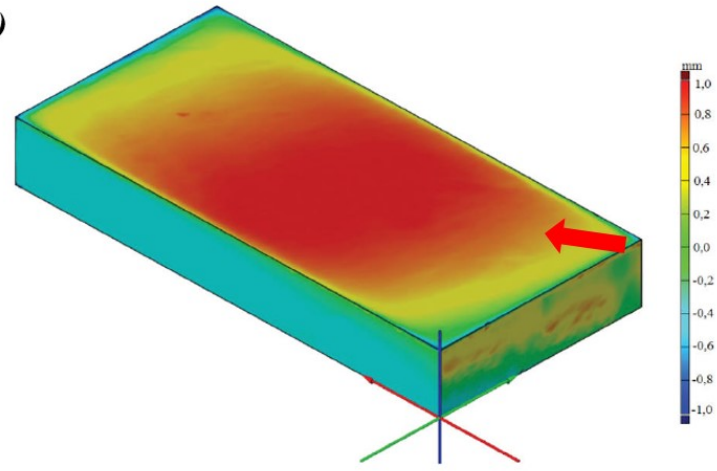

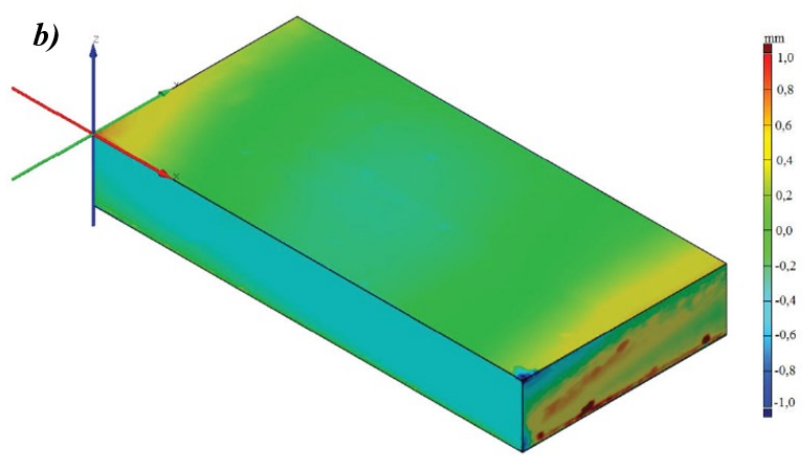

Figure 5. Colour deviation map of the bimetal; a) top view, b) bottom view [12].
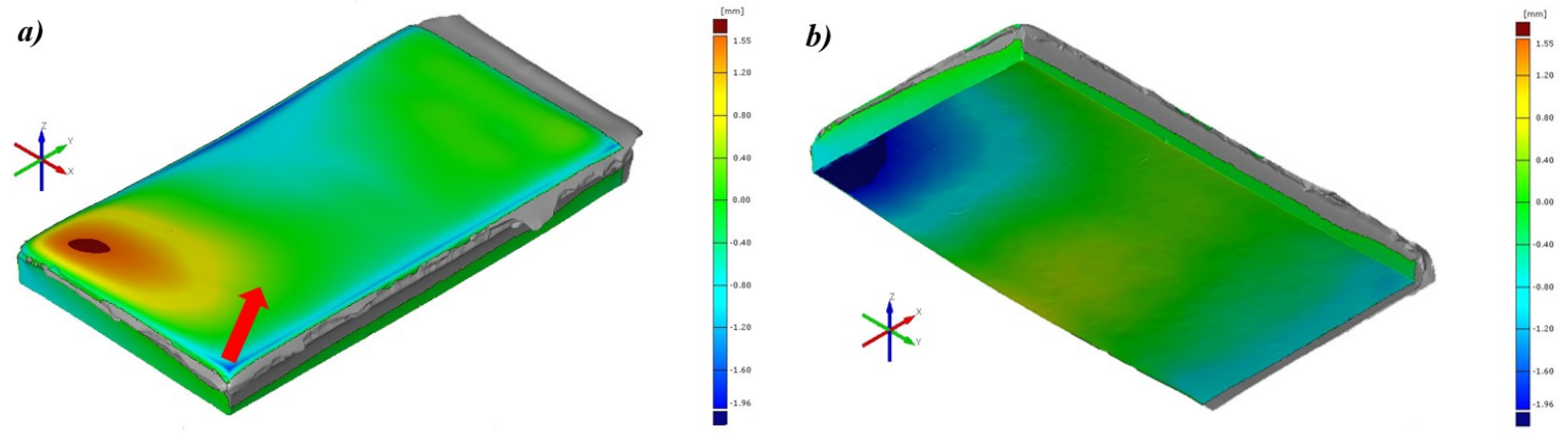

Figure 6. Colour deviation map of the bimetal; a) top view, b) bottom view [10].

\section{ACKNOWLEDGEMENTS}

Publication of this paper was supported by VEGA project of the Ministry of Education, Science, Research and Sport of the Slovak Republic, 1/0470/14 - Utilization of modern optical 3D scanning methods for weldment deformation analysis.

\section{REFERENCES}

[1] TURŇA, M.: The special welding methods, Bratislava: Alfa, 1989, 379 p., ISBN 80-05-00097-90

[2] MARÔNEK, M.: Welding metals by explosion, Bratislava: STU, 2009, 147 p., ISBN 978-80-227-3128-7

[3] MARÔNEK, M., BÁRTA, J.: Multimedia Guide of Welding Technology, Trnava: AlumniPress, 2008, 328 p., ISBN 978-80-8096-066-7

[4] KÁLNA, K.: The welding stress and deformation, Bratislava: Weldtech, 1998, 50 p., ISBN 80-88734-25-8

[5] OLABI, A. G., LORZA, R. L., BENYOUNIS, K. Y.: Quality control in welding process, In: Comprehensive Materials Processing, Volume 6: Welding and Bonding Technologies, 2014, 193-212 pp., [2014-12-28], DOI:10.1016/B978-0-08-096532-1.00607-5

[6] ATOS TipleScan: User Manual - Hardware. https://support.gom.com, 47 p., [2014-11-01]
[7] ATOS V7 Hardware - Benutzerinformation - ATOS I, ATOS I SO. https://support.gom.com, 64 p., [2014-11-01]

[8] ATOS V7.5 SR2 Manual Advanced - Scanning with ATOS - Advanced/Units A-C. https://support.gom.com, 44 p. [2014-11-01]

[9] ATOS V7.5 SR2 Manual Basic - Scanning with ATOS - Basic/Units A-J. https://support.gom.com 104 p. [2014-11-01]

[10] JÁŇA, M.: The effect of atmosphere and vacuum on character of welded joints fabricated by explosion, Master thesis. Trnava: STU in Bratislava, 2012, 95 p.

[11] ASM Handbook Volume 2, Properties and Selection: Nonferrous Alloys and Special-Purpose Materials, ASM International, 1990, 1328 p., ISBN: 978-0-087170-378-1

[12] ONDRUŠKA, M.: Explosion welding of malleable cast iron with other metals, Dissertation thesis. Trnava: STU in Bratislava, 2012, $132 \mathrm{~s}$.

[13] BENÁK, M.: Physicometallurgical aspects of explosion bonding of dissimilar metals, Dissertation thesis. Trnava: STU in Bratislava, 2011, $160 \mathrm{~s}$. 